\title{
Propelling ST-segment elevation myocardial infarction systems of care into the air
}

\author{
Amish N. Raval', Amy Shepard² \\ 1 Division of Cardiovascular Medicine, Department of Medicine, University of Wisconsin School of Medicine and Public Health, Madison, Wisconsin, United States \\ 2 University of Wisconsin-Health, Madison, Wisconsin, United States
}

RELATED ARTICLE by Świeżewski et al, see p. 284

Correspondence to: Amish N. Raval, MD, FACC, FAHA, Division of Cardiovascular Medicine, Department of Medicine, University of Wisconsin School of Medicine and Public Health, H4/568 Clinical Sciences Center, 600 Highland Avenue, Madison, Wisconsin, 53792, United States, phone: +16082630836, email: anr@medicine.wisc.edu Received: March 25, 2020. Accepted: March 26, 2020. Published online: April 24, 2020 Kardiol Pol. 2020; 78 (4): 265-266 doi:10.33963/KP.15300 Copyright by the Author(s), 2020
Prompt recognition and early coronary artery reperfusion are the cornerstones of any ST-segment elevation myocardial infarction (STEMI) systems of care. American and European guidelines recommend rapid transport of patients to a STEMI receiving center capable of high-quality primary percutaneous coronary intervention (PCI), if first medical contact to PCI reperfusion can be achieved within 120 minutes. ${ }^{1,2}$ The boundary between rural and urban areas has typically been assigned by civil boundaries. It has been long understood that geographic disparities exist for many rural communities that are too distant to reliably provide timely STEMI transport. As urban cities expand in population density and geographic size, timely STEMI transport is jeopardized due to distances from fringes of those areas and congested traffic patterns. The alternative to primary PCI defaults to primary thrombolytic therapy; however, the wealth of clinical trial evidence indicates that thrombolytic therapy is associated with worse ischemic and bleeding outcomes in comparison with timely PCI. The integration of helicopter emergency medical services (HEMS) in modern STEMI systems of care has improved the timeliness of transport of these patients and improved outcomes. ${ }^{3,4}$

In this issue of Kariologia Polska (Kardiol Pol, Polish Heart Journal) Świeżewski et al ${ }^{5}$ investigated in their retrospective analysis the patient characteristics and early outcomes of more than 6000 patients with STEMI that were transferred from rural and urban communities to STEMI receiving centers in Poland. The authors observed that HEMS facilitated efficient interhospital transport of patients with STEMI for PCI, and patients who were transported from rural locations had

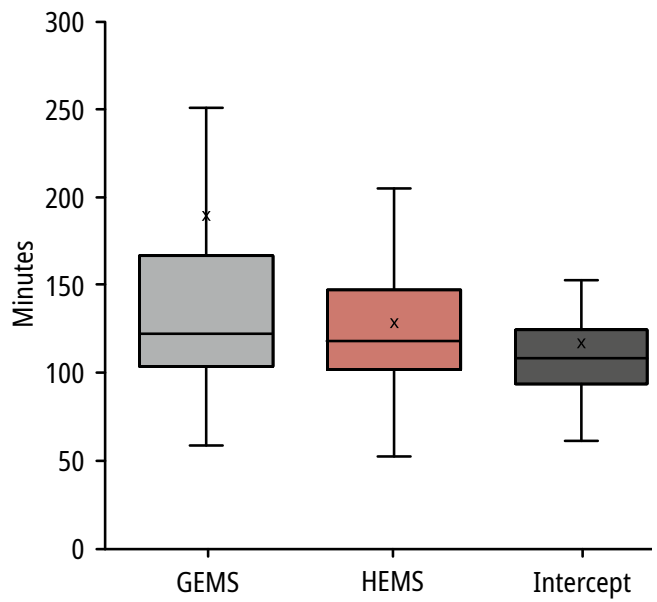

FIGURE 1 Box and whisker plot showing the time from the first medical contact to percutaneous coronary intervention reperfusion in patients transferred from a rural location to the University of Wisconsin-Madison STEMI receiving center by ground emergency medical services (GEMS; $n=219)$, helicopter emergency medical services (HEMS; $n=260)$, or intercepted by HEMS from GEMS $(n=20)$ from January 1, 2015 to September 30, 2019. Despite similar overall distances travelled, HEMS intercepting with GEMS demonstrated the lowest median transfer times $(P<0.03$, paired $t$ test). The bottom whisker, bottom edge of the box, top edge of the box, and top whisker indicate the 5th, 25th, 75th, and 95th percentiles, respectively. The $x$ symbol represents the median value (50th percentile). The horizontal line represents the mean.

a greater prevalence of hemodynamic compromise presumably due to delays in STEMI recognition. Although the authors do not characterize in-hospital outcomes, the use of thrombolytic therapy, and how often HEMS could not be 
dispatched due to weather conditions, the overall HEMS STEMI transport effort seems favorable for patients with STEMI in and around Poland.

Notably, the authors describe close coordination between ground emergency medical services (GEMS) and HEMS and this was particularly evident for rural transport. In our own institution's experience involving STEMI transport from rural Wisconsin between 2015 and 2019, HEMS intercept with GEMS at designated sites was associated with the lowest first medical contact to coronary reperfusion times, in comparison with GEMS and HEMS transfer alone, despite similar median distances travelled (FIGURE1). Gunnarsson et $\mathrm{al}^{3}$ observed that having physicians on board HEMS for STEMI transport improved in-hospital outcomes.

Modern HEMS systems are equipped with enhanced aviation safety technology and are now capable of transporting patients in shock with percutaneous circulatory and oxygenation support devices. Unfortunately, little is understood regarding the financial cost implications of HEMS for STEMI transport in the United States, Europe, and elsewhere. In another example, the cost-effectiveness of HEMS for the transfer of trauma patients is dependent upon the mortality and morbidity reduction that the HEMS transfer affords and over-triage of patients with minor injuries. ${ }^{6}$ Until such data are available, judicious utilization of HEMS for STEMI transfer to enable timely primary PCI seems to be a reasonable use of this resource within the framework of a comprehensive STEMI system of care.

\section{ARTICLE INFORMATION}

DISCLAIMER The opinions expressed by the author are not necessarily those of the journal editors, Polish Cardiac Society, or publisher.

CONFLICT OF INTEREST None declared.

OPEN ACCESS This is an Open Access article distributed under the terms of the Creative Commons Attribution-NonCommercial-NoDerivatives $4.0 \mathrm{In}$ ternational License (CC BY-NC-ND 4.0), allowing third parties to download articles and share them with others, provided the original work is properly cited, not changed in any way, distributed under the same license, and used for noncommercial purposes only. For commercial use, please contact the journal office at kardiologiapolska@ptkardio.pl.

HOW To CITE Raval AN, Shepard A. Propelling ST-segment elevation myocardial infarction systems of care into the air. Kardiol Pol. 2020; 78: 265-266. doi:10.33963/KP.15300

\section{REFERENCES}

1 O'Gara PT, Kushner FG, Ascheim DD, et al; American College of Cardiology Foundation/American Heart Association Task Force on Practice Guidelines. 2013 ACCF/AHA guideline for the management of ST-elevation myocardial infarction: a report of the American College of Cardiology Foundation/American Heart Association Task Force on Practice Guidelines. Circulation. 2013; 127: e362-425.

2 Ibanez B, James S, Agewall S, et al; Group ESCSD. 2017 ESC Guidelines for the management of acute myocardial infarction in patients presenting with ST-segment elevation: the Task Force for the management of acute myocardial infarction in patients presenting with ST-segment elevation of the European Society of Cardiology (ESC). Eur Heart J. 2018; 39: 119-177.

3 Gunnarsson SI, Mitchell J, Busch MS, et al. Outcomes of physician-staffed versus non-physician-staffed helicopter transport for ST-elevation myocardial infarction. J Am Heart Assoc. 2017; 6: e004936.

4 Schneider MA, McMullan JT, Lindsell C], et al. Reducing door-in door-out intervals in helicopter ST-segment elevation myocardial infarction interhospital transfers. Air Med J. 2017; 36: 244-247.
5 Świeżewski SP, Wejnarski A, Leszczyński PK, et al. Characteristics of urban versus rural utilization of the Polish Helicopter Emergency Medical Service in patients with ST-segment elevation myocardial infarction. Kardiol Pol. 2020; 78: 284-291.

6 Delgado MK, Staudenmayer KL, Wang NE, et al. Cost-effectiveness of helicopter versus ground emergency medical services for trauma scene transport in the United States. Ann Emerg Med. 2013; 62: 351-64.e19. 